International Journal of

Environmental Research and

Public Health

ISSN 1660-4601

www.mdpi.com/journal/ijerph

Article

\title{
Changes in Active Commuting to School in Czech Adolescents in Different Types of Built Environment across a 10-Year Period
}

\author{
Jan Dygrýn *, Josef Mitáš, Aleš Gába, Lukáš Rubín and Karel Frömel \\ Faculty of Physical Culture, Palacký University, Olomouc 771 11, Czech Republic; \\ E-Mails: josef.mitas@upol.cz (J.M.); ales.gaba@upol.cz (A.G.); lukas.rubin@upol.cz (L.R.); \\ karel.fromel@upol.cz (K.F.) \\ * Author to whom correspondence should be addressed; E-Mail: jan.dygryn@upol.cz; \\ Tel.: +420-585-636-469.
}

Academic Editor: Brian Caulfield

Received: 3 August 2015 / Accepted: 13 October 2015 / Published: 16 October 2015

\begin{abstract}
Active commuting (AC) to school represents a great opportunity to incorporate walking or cycling into adolescents' everyday routine. The objective of the study was to describe changes in AC in Czech adolescents across a 10-year period in different built environments. Data from the 2001 and 2011 Czech Census of Population and Housing were used to examine the mode of transportation taken to school in 6236 adolescents. Changes in AC over time were analyzed for low and high walkable areas separately in two Czech regional cities, Olomouc and Hradec Králové. Between 2001 and 2011, the proportion of adolescents actively commuting to school decreased by $47 \%$, from an absolute rate of $49.1 \%$ to $26 \%$. The proportion of active commuters fell in low walkable areas by $61 \%$ and in high walkable areas by $39 \%$. The results indicated that adolescents in 2011 were 2.7 times less $(\mathrm{OR}=0.365, p<0.001)$ likely to actively commute than in 2001. The $\mathrm{AC}$ behavior in Czech adolescents has a negative tendency to replicate travel-to-school patterns in adolescents previously described in more developed countries. The findings might serve as a recommendation for municipal policy.
\end{abstract}

Keywords: walking; cycling; physical activity; GIS; youth; transportation; census 


\section{Introduction}

Being physically active is one of the most important steps that people of all ages can take to improve their health [1]. Active commuting (AC) is defined as walking, cycling, or other forms of human-powered transport used for utilitarian purposes, e.g., transporting to work or school. [2]. Regular walking or cycling to school or work might positively affect human health, and lead specifically to body weight reduction [3] and improved cardiovascular risk profiles in children and young people [4]. AC also represents a great opportunity to incorporate walking or cycling into adolescents' everyday routine and can represent $20 \%$ to $30 \%$ of daily moderate-to-vigorous physical activity [5]. It is necessary to monitor and understand the trends and changes in $\mathrm{AC}$ because changing the mode of transport from motorized to non-motorized results in a significant decrease in local carbon dioxide emissions and noise, and other negative effects associated with the use of passenger cars [6]. In the area of sustainable development, $\mathrm{AC}$ is understood as one of the real ways of decreasing the human carbon trace, decreasing the use of motorized transport, and thereby energy consumption [7].

To successfully promote $\mathrm{AC}$ it is important to understand the factors that influence $\mathrm{AC}$. Current theoretical models indicate that, similar to complex human behavior, an individual's choice to use an active mode of transport is influenced by various factors. The most significant factors include personality characteristics (e.g., perception of barriers to AC), social environment (e.g., family support), public policy (e.g., subsidies for bike hire, discount on value-added tax), and the built environment (e.g., aesthetics, residential density, land use mix, car-free zones). In particular, environmental conditions appear to be one of the most important elements in AC behavior. Although numerous studies examined environmental correlates (e.g., residential density, connectivity, and land use mix) of active commuting in adults [8-10], there is limited evidence of studies focused on adolescents. The relationships between residential density, connectivity, and land use mix (attributes used to define the walkability of areas) and active transport in adolescents are still not well understood. Kerr [11] found that a greater walkability of a neighborhood was associated with more active commuting in respondents aged 5-18 years. However, findings for the association of active commuting with land use mix, street connectivity, and presence of busy road have been mixed [12-15]. High land use mix around the place of residence and high connectivity facilitates zone permeability. Residential density expresses potential activity or dynamics of the area. These environmental attributes are used to define the walkability of areas [16-18]. Among Czech youth, the period between 2002 and 2010 was characterized by an increasing percentage of overweight or obese individuals, increased sedentary time, and decline or stagnation of the proportion of children meeting physical activity recommendations [19]; a similar pattern can be expected in AC. To our knowledge, there is no study using census data across a 10-year period to observe changes in adolescents' AC in the Czech Republic. Therefore, the objective of the present study was to describe the changes in AC among adolescents in two Czech cities across a 10 -year period by objectively measuring built environment and sex. 


\section{Materials and Methods}

\subsection{Procedures}

The study was conducted in Olomouc and Hradec Králové, i.e., cities where built environments have been assessed in the long term as a part of the International Physical Activity and the Environment Network (IPEN) project [18,20]. Olomouc is the sixth largest city in the Czech Republic with approximately 100,000 inhabitants and a population density of 987 inhabitants per square kilometer; Hradec Králové is the eighth largest city with approximately 93,000 inhabitants and a population density of 878 inhabitants per square kilometer. As a comparison, the population density of Prague (the capital city with more than 1.2 million residents) is 2539 inhabitants per square kilometer. Data collection took place in March 2001 and 2011.

Anonymous travel-to-school data from the 2001 and 2011 Czech Census of Population and Housing were obtained from the Czech Statistical Office for the purposes of scientific research. The census covered all permanent residents on the territory of the Czech Republic at the moment of the census and all persons having long-term residence in the Czech Republic at the moment of the census.

The dataset included all adolescents aged 12-17 whose permanent residence was in Olomouc or Hradec Králové. The legal guardian of a minor child provided the travel-to-school data. The exact wording of the question is as follows: "Specify the mode/s of transport that you usually use on a single way to work or school. Select from the below: Bus (except city transport), city transport, car-driver, car-passenger, train, bicycle, motorcycle, other, none (only walking)". The sample from 2001 included 3164 adolescents and, in 2011, data from 3072 adolescents were eligible for the analysis.

\subsection{Active Commuting}

For the purposes of the study, AC is understood as commuting by walking (no means of commuting used) or cycling; thus, people who used multiple modes of transport were excluded from the analysis (most notably walking combined with public transport). Therefore, these results under-represent the total number of adolescents who walk or cycle as a part of their journey to school.

\subsection{Built Environment}

Geographic information systems (GIS) were used to analyze and calculate the walkability indexes. Most studies assess walkability according to street connectivity, residential density, and land use mix, which experts believe to be most influential on physical activity and particularly on AC. The walkability index was adapted from international studies [11,20] and calculated separately for 2001 and 2011. Details on the index are described elsewhere [16]. Walkability was defined for each census block in Olomouc and Hradec Králové. The index was calculated using the following equation: Walkability $=$ (z-score connectivity $+z$-score net residential density $+z$-score land use mix). Connectivity was defined as the number of intersections with three or more intersecting streets per square kilometer. Residential density was assessed as the number of residential units per square meter of residential area. Land use mix was assessed as evenness of distribution of building floor area of residential, commercial, institutional, and recreational development. According to the results of the 
walkability index, the census blocks were ranked and divided into deciles. The bottom four (1-4) deciles represented low and the top four (7-10) deciles represented high walkability areas. The fifth and sixth deciles were omitted from the analysis to create a separation between low and high walkability environments. The walkability index (2011) values ranged from -5.39 to 14.62 in Olomouc, and from -3.49 to 12.17 in Hradec Králové. The fact that two regions with completely different sources of data produced similar walkability values supports the face validity of the index. All calculations of the walkability index and all map layers were processed using ArcGIS software, version 10 (ESRI Inc., Redlands, CA, USA).

\subsection{Statistical Analysis}

The data analyses were conducted using IBM SPSS, version 19 (SPSS for Windows; SPSS, Chicago, IL, USA). Descriptive statistics are presented as mean and standard deviations. All analyses were performed with alpha set at 0.05 .

The changes in AC over time were analyzed by sex and for low and high walkable areas separately. Logistic regression was used to evaluate a 10-year change in AC. The AC was the dependent variable with the year of survey as the independent categorical variable; 2001 was considered the reference year. The results of a regression analysis are presented as odds ratio (OR) with a 95\% confidence interval. Change over time was calculated by dividing the difference at the two time points by the earlier time point.

\section{Results}

The analysis included data from 6236 adolescents, of which $50.1 \%$ were boys and $49.9 \%$ were girls, aged 12 to 17 years, with a mean age of $14.7 \pm 1.7$ years. In the monitored period there was a decrease in the number of adolescents walking or biking to school. Detailed information about the study sample is shown in Table 1.

Table 1. Descriptive statistic of study samples.

\begin{tabular}{lccccc}
\hline \multirow{2}{*}{ Attribute } & \multicolumn{2}{c}{$\mathbf{2 0 0 1}$} & $\mathbf{2 0 1 1}$ & $\mathbf{2 0 0 1}$ vs. 2011 \\
\cline { 2 - 6 } & $\boldsymbol{N} \%$ & $\boldsymbol{N}$ & $\mathbf{\%}$ & $\Delta^{\mathbf{a}}$ \\
\hline 12-14 years & 1656 & 52.3 & 1233 & 40.1 & $-23 \%$ \\
15-17 years & 1508 & 47.7 & 1839 & 59.9 & $26 \%$ \\
Total sample & 3164 & 100 & 3072 & 100 & \\
\hline \multicolumn{5}{c}{ Mode of transport } \\
\hline Only walking & 1466 & 46.3 & 769 & 25.0 & $-46 \%$ \\
Bicycle & 88 & 2.8 & 29 & 0.9 & $-68 \%$ \\
City transport & 1468 & 46.4 & 1683 & 54.8 & $18 \%$ \\
Bus & 73 & 2.3 & 258 & 8.4 & $265 \%$ \\
Car-passenger & 28 & 0.9 & 110 & 3.6 & $300 \%$ \\
Others & 41 & 1.3 & 223 & 7.3 & $462 \%$ \\
Total sample & 3164 & 100 & 3072 & 100 & \\
\hline
\end{tabular}

a Relative change in proportion of respondents between 2001 and 2011. 
Between 2001 and 2011, there was a change of the built environment related to the walkability of the area. In Olomouc, residential density decreased by 9\%, respectively, from 5602.3 in 2001 to 5092.8 person $/ \mathrm{km}^{2}$ in 2011. Connectivity decreased by $10 \%$, respectively, from 48.2 to 43.6 intersection $/ \mathrm{km}^{2}$. In Hradec Králové, residential density decreased by 3\%, respectively, from 4481.6 in 2001 to 4351.5 person $/ \mathrm{km}^{2}$ in 2011. Connectivity decreased by $11 \%$, respectively, from 36.4 to 32.5 intersection $/ \mathrm{km}^{2}$.

During the monitored period, in both low and high walkable areas, we observed a decrease in the proportion of adolescents actively commuting (combined walking and cycling) to school by $47 \%$ (relative decrease), from an absolute rate of $49.1 \%$ to $26.0 \%$ (Table 2). The proportion of active commuters fell by $61 \%$ in low walkable areas (from $37.4 \%$ to $14.6 \%$ ) and in high walkable areas by $39 \%$ (from $54.5 \%$ to $33.2 \%$ ). The logistic regression showed that adolescents in 2011 were 2.7 times less likely $(\mathrm{OR}=0.365, p<0.001)$ to actively commute than in 2001. Adolescents living in low walkable areas were 3.5 less likely $(\mathrm{OR}=0.285, p<0.001)$ to actively commute than in 2001 and those living in high walkable areas were 2.4 times less likely $(\mathrm{OR}=0.416, p<0.001)$ to actively commute in 2011 than in 2001. The highest decrease in AC was found identically in boys and girls from low walkable areas, and the lowest decrease was found in boys from high walkable areas. There were no differences in changes of AC by sex.

Table 2. Changes in active commuting to school between 2001 and 2011 by sex and type of walkable area.

\begin{tabular}{|c|c|c|c|c|c|c|c|c|}
\hline \multirow{2}{*}{ Type of WA } & \multicolumn{2}{|c|}{2001} & \multicolumn{2}{|c|}{2011} & \multicolumn{4}{|c|}{2001 vs. 2011} \\
\hline & $N$ & $\%$ of $\mathrm{AC}$ & $N$ & $\%$ of $\mathrm{AC}$ & $\Delta^{\mathrm{a}}$ & OR $^{\mathbf{b}}$ & $95 \%$ CI & $p$-Value \\
\hline \multicolumn{9}{|c|}{ Boys } \\
\hline Low & 508 & 38.8 & 599 & 15.0 & $-61 \%$ & 0.279 & $0.210-0.372$ & $<0.001$ \\
\hline High & 1079 & 55.8 & 936 & 36.0 & $-35 \%$ & 0.446 & $0.373-0.533$ & $<0.001$ \\
\hline All areas & 1587 & 50.3 & 1535 & 27.8 & $-45 \%$ & 0.380 & $0.328-0.441$ & $<0.001$ \\
\hline \multicolumn{9}{|c|}{ Girls } \\
\hline Low & 489 & 36.0 & 596 & 14.1 & $-61 \%$ & 0.292 & $0.217-0.392$ & $<0.001$ \\
\hline High & 1088 & 53.2 & 941 & 30.5 & $-43 \%$ & 0.386 & $0.321-0.463$ & $<0.001$ \\
\hline All areas & 1577 & 47.9 & 1537 & 24.1 & $-50 \%$ & 0.346 & $0.297-0.404$ & $<0.001$ \\
\hline \multicolumn{9}{|c|}{ Total sample } \\
\hline Low & 997 & 37.4 & 1195 & 14.6 & $-61 \%$ & 0.285 & $0.232-0.350$ & $<0.001$ \\
\hline High & 2167 & 54.5 & 1877 & 33.2 & $-39 \%$ & 0.416 & $0.366-0.473$ & $<0.001$ \\
\hline All areas & 3164 & 49.1 & 3072 & 26.0 & $-47 \%$ & 0.365 & $0.327-0.404$ & $<0.001$ \\
\hline
\end{tabular}

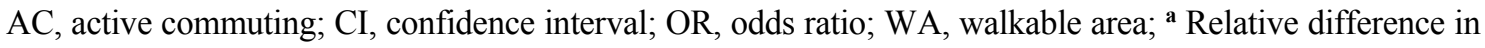
percentage of actively commuting between 2011 and 2001; ${ }^{\mathbf{b}}$ Cohort from year 2001 is a reference group.

Between 2001 and 2011, the proportion of adolescents walking to school decreased by $46 \%$ (relative decrease), from an absolute rate of $46.3 \%$ to $25.0 \%$ (Table 3 ). In low walkable areas the decline was $60 \%$ (from $34.6 \%$ to $13.7 \%$ ), and in high walkable areas the decline was $38 \%$ (from $51.7 \%$ to $32.2 \%$ ). The results of logistic regression showed that, in 2011, adolescents were less likely (OR $=0.387$, $p<0.001)$ to walk to school than those in 2001. Adolescents living in low walkable areas were less likely $(\mathrm{OR}=0.301, p<0.001)$ to walk to school in 2011 than those in 2001 and, in 2011, those living in high walkable areas were less likely $(\mathrm{OR}=0.444, p<0.001)$ to walk to school than adolescents in 
2001. The highest decrease in relative change (61\%) of walking to school between 2001 and 2011 was found in boys from low walkable areas, and the lowest change (33\%) was found in boys from high walkable areas.

Table 3. Changes in walking to school between 2001 and 2011 by sex and type of walkable area.

\begin{tabular}{|c|c|c|c|c|c|c|c|c|}
\hline \multirow{2}{*}{$\begin{array}{l}\text { Type of } \\
\text { WA }\end{array}$} & \multicolumn{2}{|r|}{2001} & \multicolumn{2}{|r|}{2011} & \multicolumn{4}{|c|}{2001 vs. 2011} \\
\hline & $N$ & $\%$ of Walkers & $N$ & $\%$ of Walkers & $\Delta^{\mathbf{a}}$ & $\mathbf{O R}^{\mathbf{b}}$ & $95 \%$ CI & $p$-Value \\
\hline \multicolumn{9}{|c|}{ Boys } \\
\hline Low & 508 & 34.4 & 599 & 13.5 & $-61 \%$ & 0.298 & $0.221-0.401$ & $<0.001$ \\
\hline High & 1079 & 51.0 & 936 & 34.3 & $-33 \%$ & 0.502 & $0.419-0.601$ & $<0.001$ \\
\hline All areas & 1587 & 45.7 & 1535 & 26.2 & $-43 \%$ & 0.422 & $0.363-0.490$ & $<0.001$ \\
\hline \multicolumn{9}{|c|}{ Girls } \\
\hline Low & 489 & 34.8 & 596 & 13.9 & $-60 \%$ & 0.304 & $0.226-0.409$ & $<0.001$ \\
\hline High & 1088 & 52.5 & 941 & 30.2 & $-42 \%$ & 0.391 & $0.326-0.470$ & $<0.001$ \\
\hline All areas & 1577 & 47.0 & 1537 & 23.9 & $-49 \%$ & 0.354 & $0.304-0.413$ & $<0.001$ \\
\hline \multicolumn{9}{|c|}{ Total sample } \\
\hline Low & 997 & 34.6 & 1195 & 13.7 & $-60 \%$ & 0.301 & $0.244-0.371$ & $<0.001$ \\
\hline High & 2167 & 51.7 & 1877 & 32.2 & $-38 \%$ & 0.444 & $0.390-0.505$ & $<0.001$ \\
\hline All areas & 3164 & 46.3 & 3072 & 25.0 & $-46 \%$ & 0.387 & $0.347-0.431$ & $<0.001$ \\
\hline
\end{tabular}

CI, confidence interval; OR, odds ratio; WA, walkable area; ${ }^{a}$ Relative difference in percentage of actively commuting between 2011 and 2001; ${ }^{\mathbf{b}}$ Cohort from year 2001 is a reference group.

A similar pattern occurred for cycling to school with a relative decrease by $68 \%$ and $71 \%$. respectively. in low walkable areas and by $64 \%$ in high walkable areas (Table 4). The highest decrease in relative change (83\%) of cycling to school between 2001 and 2011 was found in girls from low walkable areas, and the lowest change (57\%) was found in girls from high walkable areas. The results of logistic regression showed that in 2011 adolescents were less likely $(\mathrm{OR}=0.333, p<0.001)$ to cycle to school than in 2001.

Table 4. Changes in cycling to school between 2001 and 2011 by sex and type of walkable area.

\begin{tabular}{|c|c|c|c|c|c|c|c|c|}
\hline \multirow{2}{*}{$\begin{array}{l}\text { Type of } \\
\text { WA }\end{array}$} & \multicolumn{2}{|r|}{2001} & \multicolumn{2}{|r|}{2011} & \multicolumn{4}{|c|}{2001 vs. 2011} \\
\hline & $N$ & \% of Cyclists & $N$ & $\%$ of Cyclists & $\Delta^{\mathrm{a}}$ & $\mathbf{O R}^{\mathbf{b}}$ & $95 \% \mathrm{CI}$ & $p$-Value \\
\hline \multicolumn{9}{|c|}{ Boys } \\
\hline Low & 508 & 4.3 & 599 & 1.5 & $-65 \%$ & 0.337 & $0.154-0.739$ & 0.007 \\
\hline High & 1079 & 4.8 & 936 & 1.7 & $-65 \%$ & 0.343 & $0.195-0.606$ & $<0.001$ \\
\hline All areas & 1587 & 4.7 & 1535 & 1.6 & $-66 \%$ & 0.339 & $0.214-0.536$ & $<0.001$ \\
\hline \multicolumn{9}{|c|}{ Girls } \\
\hline Low & 489 & 1.2 & 596 & 0.2 & $-83 \%$ & 0.432 & $0.114-1.632$ & 0.216 \\
\hline High & 1088 & 0.7 & 941 & 0.3 & $-57 \%$ & 0.135 & $0.016-1.128$ & 0.064 \\
\hline All areas & 1577 & 0.9 & 1537 & 0.3 & $-67 \%$ & 0.291 & $0.096-0.887$ & 0.030 \\
\hline \multicolumn{9}{|c|}{ Total sample } \\
\hline Low & 997 & 2.8 & 1195 & 0.8 & $-71 \%$ & 0.292 & $0.141-0.604$ & 0.001 \\
\hline High & 2167 & 2.8 & 1877 & 1.0 & $-64 \%$ & 0.359 & $0.214-0.604$ & $<0.001$ \\
\hline All areas & 3164 & 2.8 & 3072 & 0.9 & $-68 \%$ & 0.333 & $0.218-0.508$ & $<0.001$ \\
\hline
\end{tabular}

CI, confidence interval; OR, odds ratio; WA, walkable area; ${ }^{a}$ Relative difference in percentage of actively commuting between 2011 and 2001; ${ }^{\mathbf{b}}$ Cohort from year 2001 is a reference group. 


\section{Discussion}

The results of the present study indicate that the proportion of adolescents walking or cycling to school decreased between 2001 and 2011. A relative as well as an absolute increase in the number of adolescents using the passive mode of transport to school were observed for city transport, bus, and car-passenger. This finding is in line with a previous study of Czech youth pointing to increase of sedentary time and a decline or stagnation of the proportion of children meeting physical activity recommendations [19]. According to another study [21], a substantial part of Czech boys and girls (aged 11-15) do not participate in moderate-to-vigorous physical activity and vigorous physical activity as recommended. This decrease in $\mathrm{AC}$ might be associated with the social and economic transformation of Czech society and the fact that lifestyle changes have a tendency to replicate travel-to-school patterns that have been previously observed in the U.S. [22], Australia [23], Canada [24], the UK [25], and Spain [26].

Our results provide evidence that a proportion of adolescents walking or cycling to school is indeed linked to neighborhood environment characteristics. These findings are in agreement with other studies [27-29]. The decline of active commuters was stronger in low walkable areas than in high walkable areas. The findings suggest that the type of built environment influences the prevalence of $\mathrm{AC}$ to school and even influences the degree of decrease over time. Similar patterns were observed for both walking and cycling. Our findings may be explained by proximity to school in high walkable areas and by the fact that parents who live in high walkable areas are less likely to use cars (short distances between places and good access to public transport).

Consistent with previously published studies [29-31], walking was the most common mode of AC to school. On the other hand, in Belgium, where $58.4 \%$ of adolescents commuted actively to school, $88.7 \%$ of these active commuters cycled to school and $11.3 \%$ walked to school [32]. Studies examining barriers to $\mathrm{AC}$ have identified the distance between destinations and street safety as an important parental concern [11,33]. For walking-only journeys, the generally considered distance is approximately $2 \mathrm{~km}[34,35]$. Our data analysis did not include distance variables and this limitation must be taken into account while interpreting the results. We demonstrated no sex differences in AC to school of Czech adolescents. This results are consistent with previous Czech research of AC of adolescents [36], but inconsistent with the results that have been reported in AC among boys and girls in the U.S. [23], Australia [23], Canada [24], the UK [25], and Spain [26].

There were some limitations in our study. The national census is one of the most extensive statistical surveys. It provides a great number of valuable data which cannot be effectively collected in any other way. However, the census does not ask about walking or cycling for recreation or sport and therefore underestimates the total walking and cycling. It is necessary to mention that AC is strongly affected by seasonality. For our purposes we excluded all journeys with more than one mode of transport from active transport, which led to underestimation of the total transportation of walking or cycling. Another limitation might be the fact that we are not able to verify whether the decrease in AC between 2001 and 2011 could be influenced by extended distances between schools and homes of adolescents. The changes in AC of adolescents may be also influenced by intense use of cars by adults, because there was a $41 \%$ increase (from 345 to 485 cars) in the number of automobiles per 1000 inhabitants between 2001 and 2011. Changes in attributes of the built environment not observed in our study could 
have happened during the 10-year period of 2001-2011, which also might be the source of the decrease in AC. A strength of the study is the large sample from the census data. Another strength is the application of objective assessment of environmental characteristics using the GIS separately for 2001 and 2011.

\section{Conclusions}

This study demonstrate that adolescents' AC to school significantly decreased between 2001 and 2011 and was influenced by the built environment. We found that AC behavior of Czech adolescents has a tendency to replicate travel-to-school patterns of adolescents that have been previously observed in more developed countries. This finding has implications for the broader research community and it might serve as a recommendation for municipal policy. Increasing AC can have positive benefits for communities and it can also improve the health of individuals.

\section{Acknowledgments}

This study was supported by the research grant of the Czech Science Foundation (No. 14-28696S) "Multifactorial research on built environment, active lifestyle and physical fitness in Czech adolescents".

\section{Author Contributions}

Jan Dygrýn conceptualized and designed the study, conducted the analyses, and wrote the draft of the manuscript. Josef Mitás supervised data collection and assisted with writing the manuscript. Aleš Gába assisted with the analyses and writing the manuscript. Lukáš Rubín assisted with writing the manuscript. Karel Frömel provided critical revision on the manuscript drafts. All co-authors reviewed, revised, and approved the final manuscript.

\section{Conflicts of Interest}

The authors declare no conflict of interest.

\section{References}

1. Centers for Disease Control and Prevention. State Indicator Report on Physical Activity, 2014; U.S. Department of Health and Human Services: Atlanta, GA, USA, 2014.

2. Sallis, J.F.; Frank, L.D.; Saelens, B.E.; Kraft, M.K. Active transportation and physical activity: Opportunities for collaboration on transportation and public opportunities health research. Transp. Res. Part A Policy Pract. 2004, 38, 249-268.

3. Lindstrom, M. Means of transportation to work and overweight and obesity: A population-based study in southern Sweden. Prev. Med. 2008, 46, 22-28.

4. Andersen, L.B.; Harro, M.; Sardinha, L.B.; Froberg, K.; Ekelund, U.; Brage, S.; Anderssen, S.A. Physical activity and clustered cardiovascular risk in children: A cross-sectional study (the European youth heart study). Lancet 2006, 368, 299-304. 
5. Southward, E.F.; Page, A.S.; Wheeler, B.W.; Cooper, A.R. Contribution of the school journey to daily physical activity in children aged 11-12 years. Am. J. Prev. Med. 2012, 43, 201-204.

6. Frank, L.D.; Greenwald, M.J.; Winkelman, S.; Chapman, J.; Kavage, S. Carbonless footprints: Promoting health and climate stabilization through active transportation. Prev. Med. 2010, 50, S99-S105.

7. Ewing, R.; Cervero, R. Travel and the built environment. J. Am. Plan. Assoc. 2010, 76, 265-294.

8. Van Dyck, D.; Deforche, B.; Cardon, G.; de Bourdeaudhuij, I. Neighbourhood walkability and its particular importance for adults with a preference for passive transport. Health Place 2009, 15, 496-504.

9. Badland, H.; Schofield, G. Transport, urban design, and physical activity: An evidence-based update. Transp. Res. Part D Transp. Environ. 2005, 10, 177-196.

10. Witten, K.; Blakely, T.; Bagheri, N.; Badland, H.; Ivory, V.; Pearce, J.; Mavoa, S.; Hinckson, E.; Schofield, G. Neighborhood built environment and transport and leisure physical activity: Findings using objective exposure and outcome measures in New Zealand. Environ. Health Perspect. 2012, 120, 971-977.

11. Kerr, J.; Rosenberg, D.; Sallis, J.F.; Saelens, B.E.; Frank, L.D.; Conway, T.L. Active commuting to school: Associations with environment and parental concerns. Med. Sci. Sport Exerc. 2006, 38, 787-794.

12. Timperio, A.; Ball, K.; Salmon, J.; Roberts, R.; Giles-Corti, B.; Simmons, D.; Baur, L.A.; Crawford, D. Personal, family, social, and environmental correlates of active commuting to school. Am. J. Prev. Med. 2006, 30, 45-51.

13. McMillan, T.E. The relative influence of urban form on a child's travel mode to school. Transp. Res. Part A Policy Pract. 2007, 41, 69-79.

14. Boarnet, M.G.; Day, K.; Anderson, C.; McMillan, T.; Alfonzo, M. California's safe routes to school program-Impacts on walking, bicycling, and pedestrian safety. J. Am. Plan. Assoc. 2005, 71, 301-317.

15. Wahlgren, L.; Schantz, P. Bikeability and methodological issues using the active commuting route environment scale (acres) in a metropolitan setting. BMC Med. Res. Methodol. 2011, 11, doi:10.1186/1471-2288-11-6.

16. Frank, L.D.; Sallis, J.F.; Saelens, B.E.; Leary, L.; Cain, K.; Conway, T.L.; Hess, P.M. The development of a walkability index: Application to the neighborhood quality of life study. Brit. J. Sport Med. 2010, 44, 924-933.

17. Leslie, E.; Coffee, N.; Frank, L.D.; Owen, N.; Bauman, A.; Hugo, G. Walkability of local communities: Using geographic information systems to objectively assess relevant environmental attributes. Health Place 2007, 13, 111-122.

18. Dygryn, J.; Mitas, J.; Stelzer, J. The influence of built environment on walkability using geographic information system. J. Hum. Kinet. 2010, 24, 93-99.

19. Sigmundova, D.; Sigmund, E.; Hamrik, Z.; Kalman, M. Trends of overweight and obesity, physical activity and sedentary behaviour in Czech schoolchildren: HBSC study. Eur. J. Public Health 2014, 24, 210-215. 
20. Adams, M.A.; Frank, L.D.; Schipperijn, J.; Smith, G.; Chapman, J.; Christiansen, L.B.; Coffee, N.; Salvo, D.; du Toit, L.; Dygrýn, J.; et al. International variation in neighborhood walkability, transit, and recreation environments using geographic information systems: The IPEN adult study. Int. J. Health Geogr. 2014, 13, doi:10.1186/1476-072X-13-43.

21. Kalman, M.; Hamrik, Z.; Sigmund, E.; Sigmundová, D.; Salonna, F. Physical activity of Czech adolescents: Findings from the HBSC 2010 study. Acta Gymnica 2015, 45, 3-11.

22. McDonald, N.C. Active transportation to school—-Trends among US schoolchildren, 1969-2001. Am. J. Prev. Med. 2007, 32, 509-516.

23. Van der Ploeg, H.P.; Merom, D.; Corpuz, G.; Bauman, A.E. Trends in Australian children traveling to school 1971-2003: Burning petrol or carbohydrates? Prev. Med. 2008, 46, 60-62.

24. Buliung, R.N.; Mitra, R.; Faulkner, G. Active school transportation in the greater Toronto area, Canada: An exploration of trends in space and time (1986-2006). Prev. Med. 2009, 48, 507-512.

25. Black, C.; Collins, A.; Snell, M. Encouraging walking: The case of journey-to-school trips in compact urban areas. Urban Stud. 2001, 38, 1121-1141.

26. Chillon, P.; Martinez-Gomez, D.; Ortega, F.B.; Perez-Lopez, I.J.; Diaz, L.E.; Veses, A.M.; Veiga, O.L.; Marcos, A.; Delgado-Fernandez, M. Six-year trend in active commuting to school in Spanish adolescents. Int. J. Behav. Med. 2013, 20, 529-537.

27. Tudor-Locke, C.; Ainsworth, B.E.; Popkin, B.M. Active commuting to school-An overlooked source of childrens' physical activity? Sports Med. 2001, 31, 309-313.

28. Hume, C.; Timperio, A.; Salmon, J.; Carver, A.; Giles-Corti, B.; Crawford, D. Walking and cycling to school predictors of increases among children and adolescents. Am. J. Prev. Med. 2009, 36, 195-200.

29. Dalton, M.A.; Longacre, M.R.; Drake, K.M.; Gibson, L.; Adachi-Mejia, A.M.; Swain, K.; Xie, H.; Owens, P.M. Built environment predictors of active travel to school among rural adolescents. Am. J. Prev. Med. 2011, 40, 312-319.

30. Larsen, K.; Gilliland, J.; Hess, P.; Tucker, P.; Irwin, J.; He, M. The influence of the physical environment and sociodemographic characteristics on children's mode of travel to and from school. Am. J. Public Health 2009, 99, 520-526.

31. Evenson, K.R.; Huston, S.L.; McMillen, B.J.; Bors, P.; Ward, D.S. Statewide prevalence and correlates of walking and bicycling to school. Arch. Pediatr. Adolesc. Med. 2003, 157, 887-892.

32. Van Dyck, D.; de Bourdeaudhuij, I.; Cardon, G.; Deforche, B. Criterion distances and correlates of active transportation to school in Belgian older adolescents. Int. J. Behav. Nutr. Phys. Act. 2010, 7, doi:10.1186/1479-5868-7-87.

33. Buehler, R.; Pucher, J.; Merom, D.; Bauman, A. Active travel in Germany and the U.S. Contributions of daily walking and cycling to physical activity. Am. J. Prev. Med. 2011, 41, 241-250.

34. Frank, L.D.; Sallis, J.F.; Conway, T.L.; Chapman, J.; Saelens, B.E.; Bachman, W. Many pathways from land use to health-Associations between neighborhood walkability and active transportation, body mass index, and air quality. J. Am. Plan. Assoc. 2006, 72, 75-87. 
35. Panter, J.R.; Jones, A.P.; van Sluijs, E.M.F. Environmental determinants of active travel in youth: A review and framework for future research. Int. J. Behav. Nutr. Phy. Act. 2008, 5, doi:10.1186/1479-5868-5-34.

36. Pavelka, J.; Sigmundová, D.; Hamř́k, Z.; Kalman, M. Active transport among Czech school-aged children. Acta Univ. Palacki. Olomuc. Gymn. 2012, 42, 17-26.

(C) 2015 by the authors; licensee MDPI, Basel, Switzerland. This article is an open access article distributed under the terms and conditions of the Creative Commons Attribution license (http://creativecommons.org/licenses/by/4.0/). 